\title{
EL ENFOQUE DE LA PRONUNCIACIÓN EN LIBROS DIDÁCTICOS DE ESPAÑOL COMO LENGUA EXTRANJERA EN BRASIL
}

\section{The Emphasis on Pronunciation in Coursebooks of L2 Spanish in Brazil}

\author{
Amanda RIBEIRO \\ Universidade Federal do Rio Grande \\ amandaribeiro280@gmail.com \\ https://orcid.org/0000-0003-4028-7897 \\ Bianca Valentina DA CRUZ \\ Universidade Federal do Rio Grande \\ biancavcruz04@gmail.com \\ https://orcid.org/0000-0001-9906-8264 \\ Kellen Benites de Oliveira MORAES \\ Programa de Pós-graduação em Letras \\ Universidade Federal do Rio Grande \\ kellenbenitesm@gmail.com \\ https://orcid.org/0000-0003-4866-8408 \\ Luciene Bassols BRISOLARA \\ Universidade Federal do Rio Grande \\ lucienebrisolara@furg.br \\ https://orcid.org/0000-0001-7248-6765
}

\begin{abstract}
RESUMEN: En este trabajo nos proponemos a investigar el abordaje de la pronunciación en los libros didácticos (LD's) de español de la colección "Síntesis - Curso de lengua española", utilizada en la red pública de enseñanza de la secundaria en el Río Grande del Sur. Defendiendo la importancia del componente oral en las clases de lengua extranjera, el objetivo general de esta investigación es reflexionar sobre la enseñanza de la pronunciación en los LD's. En el transcurso del artículo, presentamos nociones acerca de la competencia comunicativa y la pronunciación; la pluralidad de la lengua española y la familiaridad entre el portugués y español, tomando como base los estudios de Alves (2012), Brisolara (2016), Honorato (2010) y también las OCEM (2006). Después de concluir que el abordaje de la pronunciación en los LD's analizados no es tan presente como las que hacen referen-
\end{abstract}

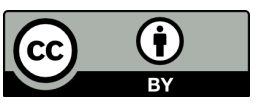


cia a la gramática y la escritura, por ejemplo, y las actividades no son suficientes, elaboramos actividades complementarias que abordan tópicos de pronunciación contemplados en los libros analizados e incentivan la práctica de la oralidad en la enseñanza de español. Esperamos que las actividades propuestas puedan auxiliar a docentes y a alumnos en la enseñanza/aprendizaje de la pronunciación en español. PALABRAS CLAVE: Pronunciación; Libros Didácticos; Enseñanza de Español; Enseñanza Secundaria.

ABSTRACT: The purpose of this work is to investigate the pronunciation approach in Spanish textbooks from the Sintesis collection Curso de Lengua española, used in the public high school system in Rio Grande do Sul. To defend the importance of the oral component in foreign language classes, the overall objective of this research is to reflect on the teaching of pronunciation in textbooks. Throughout the article, we have presented concepts of communicative competence and pronunciation, the plurality of the Spanish language and the familiarity between Portuguese and Spanish, based on the studies of Alves (2012), Brisolara (2016), Honorato (2010), and also the OCEM (2006). Having become aware that the pronunciation approach in the analyzed textbooks is not as present as the grammar and writing approach for instance, and that such activities are not enough; supplementary activities have been elaborated to address pronunciation topics covered in the assessed books which encourage the practice of orality in Spanish teaching. We hope that the proposed tasks can assist teachers and students in the teaching/learning of Spanish pronunciation. KEYWORDS: Pronunciation; Textbooks; Spanish Teaching; High School.

\section{INTRODUCCIÓN}

En este trabajo nos proponemos investigar, discutir y comprender el abordaje de la pronunciación en libros didácticos de Lengua Española, a través del análisis de los tres ejemplares pertenecientes a la colección "Síntesis - Curso de lengua española", de Ivan Martin, utilizada en la red pública de enseñanza secundaria en la ciudad de Río Grande (RS).

El objetivo general de esta investigación se basa en la reflexión sobre la enseñanza de la pronunciación en los LD's. Considerando la importancia de la enseñanza del componente oral en las clases de lengua extranjera, buscamos: (a) discutir sobre si (y cómo) se presenta la pronunciación en los libros didácticos de la colección 'Síntesis'; (b) analizar cuáles y cómo son abordados los sonidos del español; (c) investigar si los libros 
tratan de las variedades del español en lo que se refiere a la pronunciación; (d) proponer actividades prácticas que aborden la temática de la pronunciación.

En la adquisición de una lengua extranjera $(\mathrm{LE})^{1}$, son necesarios métodos de aprendizaje que van más allá de la comprensión lectora y auditiva (BUCHENER; COSTA, 2019), por esa razón creemos que el abordaje comunicativo es relevante para obtener un aprendizaje efectivo de la lengua meta. Según Alves (2012), para la adquisición de una L2, es fundamental que los estudiantes tengan la oportunidad de comunicarse. El autor también afirma que los estudiantes suelen procesar muchos aspectos fonéticos-fonológicos de la L2 como si tuvieran los mismos patrones de la L1, de ese modo, el educador debe destacar las diferencias, para que los aprendices puedan comprenderlas y procesarlas ${ }^{2}$ (ALVES, 2012). Así como, según el referido autor, es necesario que el profesor conozca con profundidad el fenómeno que va a trabajar en clase, que proporcione actividades en las que los estudiantes puedan conocer esos aspectos fonético/fonológicos y entrenarlos y que estas sean de naturaleza comunicativa. En ese sentido, defendemos la idea de que en las clases destinadas a la enseñanza de lengua española hay que tener espacio para la pronunciación, además de contenidos gramaticales, de escritura y de lectura. Gil (2007) apunta que el aspecto de la pronunciación es lo más descuidado en la enseñanza de lenguas extranjeras. Según ella, “[...] es imprescindible que el profesor incluya la buena calidad de la pronunciación de sus alumnos entre los objetivos fundamentales a los que se ha de encaminar su labor docente." (GIL, 2007, p.100).

Así, creemos que la interacción comunicativa entre los estudiantes y el conocimiento de la fonética y la fonología de los educadores de lengua extranjera son muy importantes para que los alumnos desarrollen en la práctica el idioma y que tengan contacto con el máximo de conocimiento posible acerca de la lengua.

Consideramos que las actividades didácticas pueden auxiliar a los alumnos a desarrollar las habilidades lingüísticas de la lengua extranjera. Por esa razón, tras analizar la colección Síntesis, proponemos actividades comunicativas que traten de la pronunciación y que puedan complementar el material en análisis. Este artículo se organiza, por lo tanto, de la siguiente forma: en primer lugar presentamos el aporte teórico, en el que tratamos de la competencia comunicativa y la pronunciación, la pluralidad de

\footnotetext{
${ }^{1}$ En esta investigación, utilizamos los términos LE (lengua extranjera) y L2 (segunda lengua) como sinónimos en el sentido de que son lenguas adquiridas después de la materna, no importando si se adquieren en un ambiente natural o formal.

2 Aquí usamos los términos 'comprender' y 'procesar' basándonos en las siguientes palabras de Alves (2012): "[...] 'notar' se refere a um registro consciente da ocorrência de algum aspecto isolado, 'entender' diz respeito a um reconhecimento de um princípio geral, ou seja, à capacidade de sistematização de um padrão linguístico.” (p. 212).
} 
la lengua española en los libros didácticos y la familiaridad del portugués y del español. A continuación, describimos la metodología empleada en el estudio y presentamos el análisis de los libros didácticos propuestos, hacemos comentarios sobre las reglas generales que hacen referencia a la pronunciación en el primer libro de la colección, buscamos otras informaciones más sobre pronunciación en la sección 'Para charlar y escribir', y proponemos algunas actividades que contemplen la oralidad, con énfasis en la pronunciación. Por fin, presentamos nuestras conclusiones del estudio.

\section{LA COMPETENCIA COMUNICATIVA Y LA PRONUNCIACIÓN}

La enseñanza de la pronunciación y el estímulo a la interacción deben ser constantes en clase, sea cuando se trabaja con la gramática, la lectura o la escritura, por ejemplo. Se evidencia la importancia del desarrollo de la competencia comunicativa, a través de la comprensión y la producción oral y también de la comprensión lectora y la producción escrita en el proceso de enseñanza-aprendizaje del español como lengua extranjera (ELE), en las Orientações Curriculares para o Ensino Médio (2006), documento que orienta el plan curricular de las escuelas, en el cual se proponen:

- El desarrollo de la competencia comunicativa concebida como un conjunto de componentes lingüísticos, sociolingüísticos y pragmáticos relacionados tanto al conocimiento y habilidades necesarios al procesamiento de la comunicación como a su organización y accesibilidad, así como su relación con el uso en situaciones socioculturales reales, de manera que le permita la interacción efectiva con el otro;

- El desarrollo de la comprensión oral como una forma de aproximación al otro, que permita ir más allá de lo acústico y lo superficial y lleve a la interpretación tanto de aquello que se dice (frases, textos) como de aquello que se omite (pausas, silencio, interrupciones) o de lo que se insinúa (entonación, ritmo, ironía...) y de cómo, cuándo, por qué, para qué, por quién y a quién se dice;

- El desarrollo de la producción oral, también de forma a permitir que el aprendiz se sitúe en el discurso del otro, asuma el turno y se posicione como hablante de la nueva lengua, considerando, igualmente, las 
condiciones de producción y las situaciones de enunciación de su discurso. (Op cit., p. 151)

Como se evidencia en la cita, el plan curricular de lengua extranjera también debe contemplar la oralidad, poniendo énfasis en la efectiva comunicación. Para Honorato (2010), los libros didácticos deben elaborarse pensando en el alumno, es decir, deben proponer oportunidades en las que los alumnos puedan crear enunciados y también puedan hablar. De esta manera, el aprendizaje no se limitará tan solo a la lectura, sino que contemplará también el habla. En ese sentido, la pronunciación debería ganar un mayor espacio en el aprendizaje de una LE, porque contribuye para la comprensión entre los interlocutores. No obstante, hay que aclarar que defendemos su enseñanza de forma contextualizada, no de manera exclusivamente mecanicista. En ese sentido, tomamos las palabras de Alves (2015) como referencia, una vez que, según el autor,

[...] el objetivo de la enseñanza de pronunciación es mucho mayor que la mera acuidad - es sí la comunicación, que tiene la inteligibilidad como mayor precursor. La clase de pronunciación no corresponde a un contexto aislado de enseñanza - debe estar, sí, integrada a todas las tareas comunicativas en el salón de clase, cuyo éxito depende de la interacción de los componentes lingüísticos. (Op cit., p. 406) ${ }^{4}$

Además, Alves (2012) afirma que debemos exponer los aprendices de la L2 a inputs que estén relacionados con sus respectivas realidades, es decir, las clases no deben ser solamente sobre los aspectos lingüísticos. De ese modo, reiteramos que defendemos la idea de que los libros didácticos deben abordar sus contenidos de manera contextualizada,

\footnotetext{
3 - O desenvolvimento da competência comunicativa vista como um conjunto de componentes linguísticos, sociolinguísticos e pragmáticos relacionados tanto ao conhecimento e habilidades necessários ao processamento da comunicação quanto à sua organização e acessibilidade, assim como sua relação com o uso em situações socioculturais reais, de maneira a permitir-lhe a interação efetiva com o outro;

- O desenvolvimento da compreensão oral como uma forma de aproximação ao outro, que permita ir além do acústico e do superficial e leve à interpretação tanto daquilo que é dito (frases, textos) quanto daquilo que é omitido (pausas, silêncio, interrupções) ou do que é insinuado (entonação, ritmo, ironia...) e de como, quando, por quê (sic), para quê (sic), por quem e para quem é dito; - O desenvolvimento da produção oral, também de forma a permitir que o aprendiz se situe no discurso do outro, assuma o turno e se posicione como falante da nova língua, considerando, igualmente, as condições de produção e as situações de enunciação do seu discurso. (Op cit., p. 151) ${ }^{4}[. .$.$] o objetivo do ensino de pronúncia é muito maior do que a mera acuidade -é, sim, a comunicação,$ que tem a inteligibilidade como maior precursor. A aula de pronúncia não corresponde a um contexto isolado de ensino - deve ser, sim, integrada a todas as tarefas comunicativas em sala de aula, cujo sucesso depende da interação dos componentes linguísticos. (Op cit., p. 406)
}

Revista X, v. 16, n. 5, p. 1324-1354, 2021. 
permitiendo que los estudiantes procesen la L2, a fin de que comprendan el contexto de habla, la pronunciación, y puedan interactuar con los demás y, asimismo, entender que la lengua no es homogénea, y que muchos aspectos de la pronunciación son marcas identitarias de sus hablantes.

Con relación a los conocimientos que debe tener el profesor, Alves (2019), en su estudio doctoral sobre la enseñanza de pronunciación en ELE, enumera los siguientes puntos:

Conocer la lengua materna de los estudiantes, así como los sistemas fonológicos de las dos lenguas en cuestión, utilizar los conocimientos de la interlengua de los estudiantes y aprovechar las contribuciones del Análisis de los Errores y del Análisis Contrastivo pueden ayudar en esta tarea. La fonética, la enseñanza de la pronunciación y la corrección fonética son nociones necesarias para el trabajo con la pronunciación en el salón de clase de lenguas, y son conceptos complementarios, aunque distintos. (p. 81)

Es fundamental que el profesor domine tanto la lengua extranjera que enseña, como el sistema fonológico de la LM de los aprendices, porque, como se mencionará adelante, existen transferencias de la LM en el aprendizaje de la L2. A partir de los conocimientos de ambas lenguas, el profesor podrá auxiliar a los aprendices siempre que lo necesiten.

\section{LA PLURALIDAD DE LA LENGUA ESPAÑOLA EN LOS LIBROS DIDÁC- TICOS}

La lengua española es plural y heterogénea, o sea, hay muchas variedades del español por el mundo. Si pensamos en el idioma como lengua materna, hay 21 países en donde el español es lengua oficial. Además, dentro de cada país hay innúmeras formas de hablar el idioma, sin que la comunicación se pierda. Por esa razón, queremos investigar si los libros didácticos analizados presentan la variación del idioma o si los manuales

\footnotetext{
${ }^{5}$ Conhecer a língua materna dos estudantes, bem como os sistemas fonológicos das duas línguas em questão, lançar mão dos conhecimentos sobre a interlíngua dos estudantes e aproveitar as contribuições da Análise de Erros e da Análise Contrastiva podem ser de grande ajuda nesse labor. A fonética, o ensino de pronúncia e a correção fonética são saberes necessários para o trabalho com a pronúncia em sala de aula de línguas, sendo conceitos complementares, embora distintos. (p. 81)
} 
presentan la lengua de forma estática. De acuerdo con las Orientações Curriculares para o Ensino Médio (2006),

El prestigio de alguna variedad sobre otra parece pesar, a punto de que algunos definan como estándar la variedad castellana del Español peninsular, particularmente la predominante en Madrid. Esa definición está marcada por ciertas representaciones respecto de qué son las lenguas y, en especial, por cuestiones de carácter político e ideológico las cuales no podemos dejar de estar atentos. $(\text { Op cit., p.135 })^{6}$

Es importante que consideremos que cada profesor de español usa una variante del idioma sea porque vive o vivió en una determinada región en la que, por ejemplo, hace frontera con un país de habla hispánica, o porque, al estudiar la lengua, optó por una variedad (BRASIL, 2006). Todavía, cabe a los educadores mostrar a sus alumnos la existencia de la pluralidad de la lengua, dándoles la oportunidad de elegir la variante que más les guste. En vista de eso, los libros didácticos pueden dar aporte a los profesores en clase para que ellos compartan el conocimiento sobre la heterogeneidad y la riqueza de la lengua española.

Para Francis y Pontes (2014), el libro didáctico es una de las mayores herramientas que los educadores tienen en el salón de clase, y por esa razón, es fundamental que los materiales didácticos contemplen las necesidades reales de la comunicación, haciendo que los aprendices puedan entrar en contacto con la gran variedad cultural y lingüística del idioma, en este caso, el español. Asimismo, para Kauark y Oliveira (2011), se deben llevar en consideración las principales variantes del español cuando se produce un libro con fines didácticos. Así como los referidos autores, defendemos la idea de que en los libros didácticos de lengua española se deben tratar la mayor cantidad posible de variedades del idioma, no para que el alumno domine todas, sino para que tenga el conocimiento de lo rica que es la lengua estudiada.

\footnotetext{
${ }^{6} \mathrm{O}$ prestígio de alguma variedade sobre outra parece pesar, a ponto de que alguns definam como estândar a variedade castelhana do Espanhol peninsular, particularmente a predominante em Madri. Essa definição está marcada por certas representações a respeito do que são as línguas e, sobretudo, por questões de caráter político e ideológico às quais não podemos deixar de estar atentos. (Op cit., p.135)
} 


\section{LA FAMILIARIDAD DEL PORTUGUÉS Y DEL ESPAÑOL}

El hecho de que el español y el portugués sean lenguas hermanas puede presentar puntos favorables y desfavorables en el aprendizaje de la lengua meta, en el caso, el español como L2 por aprendices brasileños. La proximidad de los idiomas permite que el alumno tenga una comprensión escrita y lectora ya en los primeros contactos con la lengua extranjera, como afirman Soares y Mercedes (2019):

[...] la proximidad entre el portugués y el español que hace de los brasileños cultos, de literacidad desarrollada, "falsos principiantes" en lengua española, sobre todo en lo que concierne a la comprensión escrita, permite exponer a los estudiantes a textos auténticos de los más diversos ámbitos prácticamente desde el inicio de su periodo de aprendizaje, facilitando a priori la aproximación intercultural y dando pie, además, a la interdisciplinariedad. (SOARES; MERCEDES, 2019, p. 75)

Los aprendices brasileños de ELE son considerados "falsos principiantes", dado que suelen presentar facilidad en la comprensión lectora; por otro lado, hay que considerar que, en la práctica oral, pueden tener mayor dificultad en el aprendizaje si no perciben las diferencias fónicas entre los dos sistemas lingüísticos, es decir, del portugués, su lengua materna, y del español, la lengua meta. Buchener y Costa (2019) enfatizan que la asimilación del sistema lingüístico del español como LE es fundamental para el proceso de aprendizaje.

En ese sentido, para que el alumno consiga comunicarse oralmente y tenga seguridad en el desarrollo de la L2, el profesor necesita poner más énfasis en el componente oral, a través de actividades comunicativas realizadas en el salón de clase.

Por esa razón, el libro didáctico debe traer los aportes necesarios para que el docente consiga auxiliar el aprendiz en la producción oral, proporcionando al estudiante un aprendizaje más eficaz de la lengua.

\section{METODOLOGÍA}

\section{Descripción de la colección didáctica}

Para la realización de esta investigación, analizamos tres libros didácticos (del alumno) que pertenecen a la colección de la secundaria titulada 'Síntesis - Curso de lengua española', de Ivan Martin. Las obras fueron publicadas por la Editora Ática y fueron puestas a disposición de la red pública en los años 2012, 2013 y 2014. Integran 
el Programa Nacional do Livro e do Material Didático (PNLD) financiado por el Fundo Nacional de Desenvolvimento da Educação (FNDE) del Ministério da Educação.

Cada libro está estructurado de la siguiente forma: son ocho capítulos que tratan de diferentes temas y hay dos Apartados con otras actividades más. Los capítulos contemplan las siguientes secciones: 'Para oír y comprender'; 'Algo de vocabulario'; 'Gramática básica'; 'Para leer y reaccionar'; 'Aprende un poco más'; 'Para charlar y escribir'; 'Para leer y reflexionar’ y ‘¿Evalúate!'

En cada capítulo la comprensión auditiva, comprensión lectora, gramática y el vocabulario aparecen de forma separada, conteniendo más páginas si comparamos con la oralidad y la escritura, que están en la misma sección de una sola página por capítulo. Por lo tanto, es evidente que la oralidad no ocupa un espacio relevante en la colección.

\section{Criterios utilizados para el análisis de la colección}

Para hacer el análisis de los libros y responder los objetivos de la investigación, consideramos los siguientes interrogantes: (a) ¿Los libros didácticos tratan de la pronunciación? (b) ¿En qué unidades se verifican y cuáles son los sonidos presentados? (c) ¿Los libros trabajan con la pronunciación de segmentos vocálicos y consonánticos? (d) ¿Los libros presentan la pronunciación de variedades del español? (e) ¿Hay ejercicios que tratan de la producción de sonidos? (f) ¿Los ejercicios son mecanicistas o están relacionados con el tópico comunicativo?

Esas preguntas, así como los objetivos, orientaron el análisis de este trabajo.

\section{ANÁLISIS DE LOS LIBROS DIDÁCTICOS}

Al analizar el primer libro de la colección 'Síntesis', evidenciamos que al principio hay un pequeño cuadro sobre pronunciación en la sección 'Las letras y los sonidos', que en primera instancia parece ser de gran interés al trabajo.

\section{PRONUNCIACIÓN}

Observa algunas reglas generales:

La $\mathbf{E}$ y la $\mathbf{O}$ son siempre cerradas: café, papel, español.

En español no hay sonidos nasales: cubano, ángel.

La $\tilde{\mathbf{N}}$ tiene un sonido semejante a la NH del portugués: año, bañarse.

La $\mathbf{V}$ tiene un sonido semejante a la $\mathbf{B}$ : vaca, vuelo.

La $\mathbf{H}$ no tiene sonido en español: hoy, ahora.

La $\mathbf{Z}$ tiene sonido de $\mathbf{S} \mathbf{y}$, como has podido observar en las lecturas del texto, es pronunciada de modo distinto por hispanohablantes de regiones distintas: embarazada. 
La $\mathbf{S}$ nunca tiene el sonido que tiene la $\mathbf{Z}$ en portugués: casa, mesa.

También la $\mathbf{L} \mathbf{L}$ es pronunciada de modo distinto por hispanohablantes de regiones distintas: llena.

La $\mathbf{G}$ delante de $\mathbf{E}$ e I tiene un sonido semejante a la $\mathbf{R} \mathbf{R}$ del portugués de algunas regiones: gente, agitado.

Lo mismo sucede con JA, JE, JI, JO, JU: jamás, ajeno, ají, joven, Juan.

TI, TE, DI, DE no tienen el sonido de "tchi”, "tche", “dji”, “dje”: tía, día, gente, donde.

La $\mathbf{R}$ al comienzo de una palabra, así como $\mathbf{R R}$, tiene sonido vibrante: rojo, carrusel.

La $\mathbf{L}$ al final de las sílabas no suena como $\mathbf{U}$ : animal, él, Albania. (MARTIN, 2012a, p. 10) [grifos del autor]

Le precede a la 'Pronunciación' un texto llamado 'La luna' que está disponible para la escucha en el CD que acompaña el libro. El audio de la lectura muestra los distintos acentos que existen en algunos países de habla hispánica, no obstante, en el libro del alumno, no son informadas cuales son las variedades del español grabadas:

La luna madura embaraza la tierra, y hace que el árbol cortado siga vivo en su madera.

La luna llena alborota a los lunáticos, a los alunados, a las mujeres y a la mar.

La luna verde mata las siembras.

La luna amarilla viene con tormenta.

La luna roja trae guerra y peste.

La luna negra, luna ninguna, deja al mundo triste y al cielo mudo.

Cuando Catalina Álvarez estaba dando sus primeros pasos, alzaba los brazos al cielo sin luna y llamaba:

¡Luna, vení! (MARTIN, 2012a, p. 10)

El autor presenta algunas explicaciones sobre la pronunciación y ejemplos de uso, y estas son todas las informaciones sobre el tópico que presenta el libro. Considerando que las informaciones no se profundizan, y que, en muchos casos, no son verdaderas, presentamos a continuación algunos comentarios sobre las 'reglas generales' presentadas en esta sección. 


\section{COMENTARIOS SOBRE LAS REGLAS GENERALES}

\section{"La E y la O son siempre cerradas: café, papel, español"}

Ni siempre las vocales medias /e/ y /o/ son cerradas, pues existen contextos en que hay un cierto nivel de apertura, como hace referencia Brisolara (2016b, p. 45), con base en Tomás (2004):

[...] a) en contacto con una vibrante, independientemente si ésta sigue $o$ precede a la vocal (ejemplos, $\mathrm{p}[\varepsilon]$ rro, para la palabra 'perro', y r $[\varepsilon] \mathrm{gla}$, para 'regla'), con excepción de los casos en que la vocal va en sílaba trabada (o cerrada) por las consonantes $<\mathrm{d}>,\langle\mathrm{m}>,<\mathrm{n}\rangle,\langle\mathrm{s}\rangle,\langle\mathrm{x}\rangle \mathrm{o}$ $<\mathrm{z}>$, dado que la consonante siguiente neutraliza la vibrante, de lo que resulta una vocal cerrada, es decir [e] (ejemplos, r[e]sto, para 'resto' y r[e]nta, para 'renta'; [...]

Por otro lado, la vocal [0], también de acuerdo con Tomás (2004, p. 59), se evidencia: a) en contacto con una vibrante, independientemente si ésta sigue o precede a la vocal (ejemplos, g[0]rra, para 'gorra' y r[o]ca, para 'roca'); b) delante de $<\mathrm{j}>\mathrm{y}<\mathrm{g}>$, con sonido [x], (ejemplos, $\mathrm{h}[\mathrm{o}] \mathrm{ja}$, para 'hoja' y esc[o]ger, para 'escoger'). (Op cit., p.45)

Según la autora, $[\varepsilon]$ y [o] son alófonos de /e/ y /o/ en español; esos elementos fónicos no funcionan como fonema en el idioma a diferencia del portugués. Otra diferencia respecto de esta lengua es que el grado de apertura de estas vocales es menor que en portugués brasileño.

\section{"En español no hay sonidos nasales: cubano, ángel"}

La regla presentada en el libro no es clara, porque parece determinar que no hay ningún tipo de nasal en español, o sea, consonantes nasales o vocales nasalizadas; sin embargo, al analizar las palabras 'cubano' y 'ángel', queda claro que el autor hace referencia a las vocales. No obstante, según Quilis (1999, 2005), no hay vocales nasales en términos fonológicos, pero, en términos fonéticos, hay contextos en que las vocales sufren nasalización. En el ejemplo 'ángel', cuando la vocal [a] está en inicio absoluto seguida de consonante nasal, suele nasalizarse. Otro contexto que ocurre la nasalización, según el autor, es cuando la vocal está entre consonantes nasales en la misma sílaba; por ejemplo, 'mando', en que /a/ se nasaliza por influencia del contexto. 


\section{"La Ñ tiene un sonido semejante a la NH del portugués: año, bañarse"}

Los sonidos de la letra $<\tilde{\mathrm{n}}>$ y del dígrafo $<$ nh $>$ realmente son semejantes, pues representan ortográficamente el fonema /n/. Así se ve en los ejemplos del libro a[n]o, ba[n]arse; lo mismo ocurre en el portugués, por ejemplo, ba[n]o para 'banho'. Hay que aclarar que la explicación del libro puede confundir al alumno en el sentido de que, al hacer comparación con la ortografía de ambas lenguas, el estudiante puede no darse cuenta de que, en español, también existe la grafía 'nh', pero no se pronuncia la ' $h$ '. Por lo tanto, palabras como 'anhelo' y 'enhornar', por ejemplo, se pronuncian como [a'nelo] y [enor'nar].

\section{"La V tiene un sonido semejante a la B: vaca, vuelo"}

$\mathrm{La} / \mathrm{b} /$, cuando está en inicio absoluto o después de consonante nasal, según Quilis (1999, 2005), suele pronunciarse como [b] (ej.: [b]eso, para 'beso' y [b]uelo para 'vuelo'), o sea, los labios están totalmente cerrados. Pero, en otros contextos, su pronunciación suele ser $[\beta]$ (ca[ $\beta]$ eza, para 'cabeza' y sua[ $\beta]$ e, para 'suave'), en la producción de esta consonante los labios están entreabiertos. A diferencia del portugués, en español no existe el fonema fricativo labiodental sonoro $/ \mathrm{v} /$.

\section{"La H no tiene sonido en español: hoy, ahora"}

En el cuadro exhibido en el libro, aparece tal afirmación y los ejemplos presentados demuestran que la $<\mathrm{h}>$ no tiene influencia en la producción oral de las palabras, como comprobamos al transcribirlas fonéticamente: ['oi] y [a'ora]. Lo mismo ocurre en palabras como 'rehace', 'hormiga', 'hada' y 'huelga'. No obstante, en los vocablos 'chico', 'chocolate' y 'Chile', después de la $<\mathrm{c}>$, la $<$ h $>$ se convierte en el dígrafo $<\mathrm{ch}>\mathrm{y}$ juntas forman un nuevo sonido, [tf], como en ['tfiko], [tfoko'late] y ['tfile].

"La $\mathrm{Z}$ tiene sonido de $\mathrm{S} y$, como has podido observar en las lecturas del texto, es pronunciada de modo distinto por hispanohablantes de regiones distintas: embarazada"

En esta afirmación el autor presenta una explicación bastante simplificada de la cuestión. En primer lugar, para tratar de sonidos, hay que usar la representación entre corchetes, o sea, la ' $z$ ' tiene sonido de [s]. Además, esta pronunciación es característica de algunos países, como los países de Hispanoamérica y algunas regiones de España, como 
Andalucía y Canarias; no obstante, en otras localidades de España su producción es la interdental [ $\theta$ ] (REAL ACADEMIA ESPAÑOLA; ASOCIACIÓN DE ACADEMIAS DE LA LENGUA ESPAÑOLA, 2011). Además, incluso en países seseantes, o sea, que no hacen distinción entre /s/ y / $\theta /$, la pronunciación de la ' $\mathrm{z}$ ' va a depender de la posición en la palabra. Por ejemplo, si la consonante está en inicio de sílaba suele pronunciarse como [s], como observamos en [s]apato, para 'zapato', no obstante, si está en posición final de sílaba, se puede pronunciar como $[\mathrm{h}],[\mathrm{s}] \mathrm{o}[\mathrm{z}]$ o incluso se suprime como observamos en 'alfére[h] 'alfére[s]' 'alfére[z] 'alfére[ø]', para 'alférez'7.

Cabe aclarar que la pronunciación [z] no es igual que en portugués y que el grado de sonoridad es menor en español. El texto "La Luna", mencionado en la explicación, es leído por un argentino, un cubano, un mexicano y un español. El autor quiso llamar la atención a la palabra 'embarazada' para que los estudiantes prestaran atención en las diferencias de acentos, pero no señaliza la posibilidad de otras producciones además de [s].

\section{"La $\mathrm{S}$ nunca tiene el sonido que tiene la $\mathrm{Z}$ en portugués: casa, mesa"}

Una de las dificultades de los niños en el aprendizaje de la lengua portuguesa es distinguir los sonidos de los grafemas $<\mathrm{s}>,<\mathrm{z}>,<\mathrm{ss}>\mathrm{y}<\mathrm{c}>$ en la escritura - los dos últimos no existen en español, pero los primeros sí. La $<\mathrm{s}>$ en español, representada fonológicamente por /s/, se mantiene como sorda en contextos como: sa, se, si, so, su, como en: [so'nido] y ['kasa], para 'sonido' y 'casa', pero, en algunos países, se produce como sonora delante de consonantes sonoras, como ['mizmo] para 'mismo'. En final de sílaba puede incluso aspirarse, ejemplo, ['mihmo] o elidirse, ejemplo ['mimo].

La pronunciación va a depender de la región donde se habla español y también de la consonante de la sílaba siguiente. Si la pronunciación es de un hablante de Montevideo (Uruguay) o de Buenos Aires (Argentina), por ejemplo, es probable que haya aspiración, o sea, que se pronuncie 'e[h]tado' y 'e[h]malte', por otro lado, si es de un mexicano, probablemente será 'e[s]tado' y 'e[z]malte'. La pronunciación $[\mathrm{z}]$ ocurre debido a la asimilación de la sonoridad de la consonante siguiente $[\mathrm{m}]$, que es sonora, y no se evidencia en 'estado', porque [t] es una consonante sorda. Ya la forma aspirada sustituye tanto [s] como [z] en las regiones en que se aspira la /s/. Asimismo la elisión de /s/ también es posible en español.

\footnotetext{
${ }^{7}$ En español hay países, como México, en que hay la producción de 'z', como [z], (ej.: 'audaz' y 'arroz', pronunciado como [au'daz] y [a'roz]), pero el grado de sonoridad es muy inferior al encontrado en el portugués de Brasil. (BRISOLARA; MACHRY DA SILVA, 2020). 


\section{"También la LL es pronunciada de modo distinto por hispanohablantes de regiones distintas: llena"}

La oralidad de las palabras en español puede variar de acuerdo con la región del hablante. Según Brisolara (2016a, p. 15), "La palabra 'calle', por ejemplo, se puede pronunciar como ['kaKe], ['kaje], ['kafe], ['kaze]." Para Silva (2007), por el español ser la lengua oficial de 21 países, hay muchas formas de hablar el idioma. En este sentido, por más que la palabra tenga el mismo código ortográfico, en la oralidad puede pronunciarse de manera distinta, como ocurre con un nativo uruguayo de la capital o del interior del país, por ejemplo.

"La $\mathbf{G}$ delante de $\mathbf{E}$ e I tiene un sonido semejante a la $R R$ del portugués de algunas regiones: gente, agitado" y "Lo mismo sucede con JA, JE, JI, JO, JU: jamás, ajeno, ají, joven, Juan"

De acuerdo con Sandes (2010, p. 94-95),

En español, el sonido [x] se realiza como fricativo velar sordo en palabras que se escriben con $\langle\mathrm{j}\rangle \mathrm{y}$ con $\langle\mathrm{g}>$ antes de las vocales $/ \mathrm{e}, \mathrm{i} /$; sin embargo, el estudiante brasileño lo transforma generalmente en un sonido fricativo alveopalatal sonoro [3], pues en la lengua portuguesa tal sonido se produce de esa forma en todos los dialectos. Por esa razón, el estudiante pronuncia gente, jamón, gitano y José como [zẽtti, zamõun, zitãnu, $30 z \varepsilon] .^{8}$

En vista de eso, los aprendices brasileños tienden a pronunciar 'ge, gi, ja, je, ji, jo, ju' como si fuera [3]. Otra posibilidad de pronunciación de los estudiantes es la [x], solo que, en lugar de la realización sorda característica del español, la producen como sonora, como lo harían en 'rosa' en portugués.

\section{“TI, TE, DI, DE no tienen el sonido de ‘tchi', 'tche', 'dji', ‘dje’: tía, día, gente, donde”}

En el cuadro "pronunciación", Martin afirma que TI, TE, DI y DE no tienen sonido de 'tchi', 'tche', 'dji', 'dje'. Pero él no hace la explicación necesaria para que

\footnotetext{
${ }^{8}$ Em espanhol, o som [x] é realizado como fricativo velar surdo em palavras que se escrevem com $<\mathrm{j}>$ e com $<\mathrm{g}>$ antes das vogais /e, $\mathrm{i} /$; todavia, o estudante brasileiro o transforma geralmente num som fricativo alveopalatal sonoro [3], pois em língua portuguesa tal som é produzido dessa forma em todos os dialetos. Logo, o estudante pronuncia gente, jamón, gitano e José como [zẽt $f i$, zamõw, zitãnu, 3oze].
} 
podamos comprender este fenómeno más a fondo. Hace falta que presente un fenómeno característico de algunas variedades del portugués, que es la palatalización de /t/ y /d/ delante de la [i]. En el Río Grande del Sur, por ejemplo, estas dos consonantes se realizan como oclusivas alveolares antes de las vocales [a], $[\mathrm{e}],[\varepsilon],[\mathrm{o}],[\mathrm{o}] \mathrm{y}[\mathrm{u}]$, pero tienden a producirse como africadas, es decir, [t $\left.\int\right]$ y [dz], cuando la vocal siguiente es [i], como vemos en: [t $\mathrm{t} i$ ] gre -'tigre', [dzi]lema - 'dilema' (BRISOLARA, 2016c).

\section{"La $R$ al comienzo de una palabra, así como la $R R$, tiene sonido vibrante: rojo, carrusel"}

Este tópico no está mal, lo que falta es la complementación de que la vibrante es múltiple, o sea [r] (ej.: [r]opa, para 'ropa'), ya que en español tenemos también la vibrante simple - o 'tepe' (ej.: ca[c]o, para 'caro'), que ocurre en ataque intervocálico, como ce $[\mathrm{r}] \mathrm{o}$, en ataque complejo, como $\mathrm{p}[\mathrm{r}]$ oducir, y en coda, como ca[r]ne ${ }^{9}$. Además, la vibrante múltiple aparece en otro contexto más: en el ataque dentro de la palabra cuando precedido de [s], [n] o [l] en coda, como en los ejemplos es[r]ilanqués, en[r]edo y al[r] ededor para 'esrilanqués', 'enredo' y 'alrededor'. Aparte de eso, $<\mathrm{r}>$ es vibrante simple.

\section{"La L al final de las sílabas no suena como U: animal, él, Albania"}

De acuerdo con Brisolara (2016c), en portugués, cuando la /1/ está en posición de coda silábica se convierte, en la pronunciación, en semivocal, como en 'pape[w]' y 'ca[w]do', en estos casos no hay asimilación de la consonante siguiente. Ya en la lengua española, la /1/ en posición de coda silábica seguida de una vocal, consonante alveolar o una pausa se produce como alveolar, como en la palabra ma[1], por ejemplo.

Tras comentar todos las 'reglas generales' presentadas en el libro, necesitamos destacar que el autor también se equivoca al representar los sonidos con símbolos de la ortografía y no con símbolos fonéticos, como podemos observar, por ejemplo, en la siguiente afirmación “TI, TE, DI, DE no tienen el sonido de 'tchi', 'tche', 'dji', 'dje'”. En el próximo apartado, analizamos las actividades orales de los tres tomos de la colección Síntesis.

\footnotetext{
${ }^{9}$ En la posición de coda, la /r/ puede producirse como vibrante simple o vibrante multiple. Para más informaciones, leer HUALDE et al. (2010).
} 


\section{SOBRE LAS ACTIVIDADES EN LOS LIBROS}

Buscando más informaciones sobre la pronunciación en el libro llegamos a las actividades encontradas en la sección 'Para charlar y escribir', que trata de la oralidad y la escritura. Esta sección utiliza, en general, el vocabulario y los aspectos lingüísticos que se trabajaron en el capítulo, incluso, notamos que algunas propuestas solamente aparecen con la finalidad de tratar de la gramática.

Además, en esta misma sección, hay un cuadro llamado ‘¡Comunícate!' que presenta sugerencias de posibles preguntas y respuestas que se emplean en la LE en los contextos estudiados en la actividad.

Hay propuestas que intentan acercarse más a una situación real de comunicación oral, por ejemplo, la siguiente actividad, ubicada en el capítulo 1 del segundo libro, que trata de 'la calle': "Observa el mapa e imagina que estás caminando por La Habana, la capital cubana. Pregúntale a un compañero cómo llegar a determinado lugar" (MARTIN, 2012b, p. 17). Para la realización de la referida actividad, el LD propone la utilización de expresiones de localización, como, por ejemplo: "Por favor, ¿dónde queda la calle... / la avenida... / la plaza... [...]?” (MARTIN, 2012b, p. 17), entre otras.

Otras actividades proponen que los alumnos ejerciten exclusivamente las cuestiones gramaticales, por ejemplo, la conjugación de verbos en diferentes tiempos y se usa la temática del capítulo tan solo como plan de fondo. En una actividad sugerida en el capítulo 7, también del segundo libro, el objetivo es utilizar el pretérito indefinido a través de la realización de una entrevista. La temática estudiada en este capítulo es 'fiestas' y hay tan solo un único ejemplo de este tema; es decir, de los cinco ejemplos de preguntas y respuestas que presenta la actividad solamente uno está adecuado a la temática:

¡Comunícate!

Para preguntar sobre sucesos pasados.

¿Hiciste algo ayer? No, me quedé en casa.

¿Viste alguna película en la tele ayer? No, salí con mis hermanas.

¿No hablaron con nadie sobre eso? Sí, hablamos con unos compañeros.

¿Cómo conmemoraste tu último cumpleaños? Hice una fiesta en casa e invité a todos mis amigos.

¿Disfrutaron mucho? Bueno, nos divertimos un poco. (MARTIN, 2012b, p. 130) [grifo nuestro]

En general, evidenciamos que las páginas que tratan de la comprensión lectora y de la gramática siempre están acompañadas de textos, sea un cómic, un texto cultural o literario. Por otro lado, las páginas sobre comprensión auditiva presentan un texto que en 
general es un diálogo con su grabación en el CD de audio para que el alumno oiga el texto; la intención es que el profesor presente la grabación, haga las actividades propuestas en el libro, y después presente la parte escrita. A pesar de que la gramática presente el texto como apoyo, este se lo utiliza solamente como pretexto para la introducción de un contenido, pues no hay ninguna reflexión sobre lo leído, solamente un destaque sobre lo que se tratará, como vemos en el ejemplo del capítulo 4 en el tercer libro de la colección:

En general, se utiliza el imperativo para:

- dar instrucciones:

Pon en un papel de aluminio unas cuantas rodajas de limón rebozadas en harina y, al lado, coloca un recipiente con agua.

- dar consejos y hacer recomendaciones:

Mujer, no creas todo lo que te digan.

- dar órdenes y hacer un pedido:

Ricardo, ¡cállate!

Cierra la ventana, por favor.

- ofrecer algo:

Come un poquito de azúcar, cucaracha amiga. (MARTIN, 2012c, p. 61) [grifo del autor]

Vemos que la intención es abordar el imperativo afirmativo, ya que la tira que acompaña la instrucción contiene verbos en este modo verbal ('vaya' y 'busque') como ejemplo de lo que será trabajado. No hay ninguna reflexión sobre el contenido de la tira, o sea, la actividad es totalmente estructural. Lo mismo observamos en los tres libros contemplados en este estudio.

Al analizar los libros, percibimos que el autor considera importante la comunicación oral (aunque se aborde poco en relación con los demás tópicos), cuando propone actividades denominadas 'para charlar', sin embargo, él no dedica ningún espacio a la enseñanza de la pronunciación, y esto también es importante en el aprendizaje de una lengua extranjera, pues consideramos que además de las competencias lingüísticas lectoras, escritas y comunicativas, este conocimiento es relevante para que el alumno conozca los aspectos formales de la lengua. Al observar el Marco Común Europeo de Referencia (2002), notamos que él destaca la importancia de la competencia fónica como parte integrante de la capacidad perceptiva y productiva en el aprendizaje de la L2.

La competencia fonológica supone el conocimiento y la destreza en la percepción y la producción de: las unidades de sonido (fonemas) de la lengua y su realización en contextos concretos (alófonos); los rasgos fonéticos que distinguen fonemas (rasgos distintivos; por ejemplo: sonoridad, nasalidad, oclusión, labialidad); la composición fonética de las palabras (estructura silábica, la secuencia acentual de las palabras, 
etc.); la fonética de las oraciones (prosodia) [que incluye] acento y ritmo de las oraciones (sic) y entonación; y la reducción fonética. $(O p$ cit., p. 113-114)

Así, al hacer el análisis de los libros percibimos que casi no hay material sobre (y de) pronunciación en la colección 'Síntesis', además, hay poco incentivo a la oralidad en comparación con los demás componentes de la lengua, como la escritura y los contenidos gramaticales. Los materiales son ricos en temas de diversidad cultural y a pesar de que la colección presente la variedad del español, en la comprensión auditiva, por ejemplo, no hay una contextualización o explicaciones sobre esta temática. Esos puntos nos preocupan y nos hacen cuestionar si se está utilizando el espacio destinado a las clases de español de manera que los alumnos realmente aprendan a comunicarse en la lengua, no solo en lo referente a la producción escrita, sino también en los aspectos de la pronunciación que proporcionan un desarrollo de la producción oral y también de la comunicación propiamente dicha.

Por esta razón, proponemos, a continuación, algunas actividades que se pueden emplear como complementarias a la colección analizada y también para el perfeccionamiento de la oralidad, independientemente del uso de los libros citados. Para eso, consideramos la mayoría de los tópicos de pronunciación contemplados en Martin (2012a, p. 10). Aunque los tópicos no tengan una misma estructuración, pensamos en una variedad de actividades que utilizan la reflexión, la percepción y la discriminación de sonidos, la interpretación de los textos utilizados y la producción oral. Reiteramos que son tan solo sugerencias a los docentes y que, incluso, pueden adaptar las actividades llevando en cuenta su público de aprendices y sus dificultades.

\section{PROPUESTA DE ACTIVIDADES}

\section{Tópico: Apertura de las vocales medias}

Objetivo(s): Percibir el grado de apertura de las vocales medias en español en comparación con el portugués. Reflexión lingüística con la ayuda del profesor y de los compañeros de clase. Desarrollar la práctica comunicativa a través de la temática 'trabajo y carreras'.

Actividad 1: Escucha la pronunciación de las palabras que siguen:

Grupo A: perro, fiesta.

Grupo B: roca, moda.

Después de la audición, contesta oralmente a las siguientes preguntas:

a) ¿Se pronuncia igual la "e" en las dos palabras presentadas en el Grupo A? 
b) Y la vocal "o" en el grupo B, ¿se pronuncia igual o de forma diferente?

c) ¿Qué pasa con estos sonidos? ¿Crees que ocurre lo mismo en portugués?

Se sugiere al profesor que, después de la reflexión del grupo, ponga el audio otra vez para que los estudiantes comprueben las diferencias respecto de la pronunciación de las vocales 'e' y 'o'.

Actividad 2: Lee las palabras de la actividad 1 con dos o tres compañeros más y verifica cómo pronuncian las vocales. ¿Todos son capaces de percibir las diferencias entre la 'e' y la 'o' en cada uno de los vocablos? ¿Cómo puedo ayudar a mi compañero a mejorar su pronunciación?

Actividad 3: Imagina que eres voluntario de una ONG y vas a presentar la institución en una escuela. Prepara una presentación en la que expongas cuál es el objetivo de la institución, qué trabajos hay, cuál el público meta de la organización etc. Recuerda poner atención en la pronunciación de las vocales "e" y "o".

\section{Tópico: La nasalización de vocales}

Objetivo(s): Percibir los contextos de nasalización de vocales en español y su grado de nasalidad. Conocer uno de los acentos en español. Desarrollar la práctica comunicativa a través de la temática 'música e instrumentos musicales'.

Actividad 1: Escucha la canción "La Gozadera", del grupo cubano Gente de Zona. Pon atención en las vocales destacadas abajo:

dominicana - tambora - zạndunga - hermano - mundo - sumạndo - banndera

Después de oír la canción y de poner atención en las palabras listadas en el cuadro, contesta oralmente a las siguientes preguntas:

a) ¿Qué hay de común entre las vocales destacadas con relación a las consonantes que las rodean?

b) ¿Se pronuncia igual la vocal 'a' en las palabras 'hermano' y 'sumando’? Justifica tu respuesta.

c) ¿Y la vocal 'u' en 'zandunga' y 'mundo'? Justifica tu respuesta.

d) Escucha nuevamente la canción y busca otro ejemplo (con otra vocal) como el de la actividad anterior e identifica si la pronunciación de los vocablos es igual o diferente. Justifica tu respuesta.

Actividad 2: A partir de lo que concluyeron en la actividad anterior, discutan en parejas si lo que ocurre en español pasa también en el portugués. 
Actividad 3: Piensa que eres un(a) cantante y elige uno de los instrumentos que más te gustaría tocar: contrabajo, piano eléctrico, maracas, trompeta, pandereta, trompa, triángulo, acordeón, etc. Después, haz una búsqueda sobre informaciones de este instrumento musical y preséntala a los compañeros. Recuerda poner atención en la pronunciación de las vocales nasalizadas.

\section{Tópico: $\mathbf{L a}<\mathrm{b}>$ y la $<\mathbf{v}>$}

Objetivo(s): Percibir los distintos sonidos que las letras 'b' y 'v' representan. Desarrollar la consciencia fonológica a través de trabalenguas. Desarrollar la práctica comunicativa a través de la temática 'viviendas'.

Actividad 1: Escucha la pronunciación de las palabras que siguen y tacha la opción más adecuada respecto de los labios.

\section{Labios totalmente cerrados}

Labios entreabiertos
a) nave
b) anverso

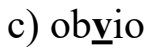
d) vosotros
e) envuelto
f) advertencia
g) olvido
h) invierno

$(\quad)$
$(\quad)$
$(\quad)$
$(\quad)$
$(\quad)$
$(\quad)$
$(\quad)$
$(\quad)$

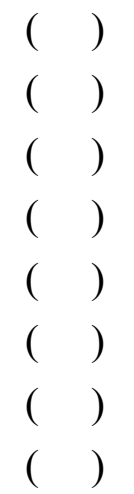

Actividad 2: En parejas, entrena los trabalenguas presentados a continuación:

a) Pablito clavó un clavito, ¿qué clavito clavó Pablito? Pablito clavó un clavito en la calva de un calvito. En la calva de un calvito, un clavito clavó Pablito.

b) Juan tuvo un tubo, y el tubo que tuvo se le rompió. Para recuperar el tubo que tuvo, tuvo que comprar un tubo igual al tubo que tuvo.

Después de entrenar los trabalenguas, comenta a qué conclusión puedes llegar sobre la pronunciación de las consonantes ' $b$ ' $y$ ' $v$ '.

Actividad 3: Imagina que tu familia y tú deciden vivir en otra ciudad y, por ello, necesitas vender la casa donde viven ahora. Elabora un anuncio de audio que puedas enviar por WhatsApp o trasmitir en la radio local. Acuérdate de que debes describir la vivienda y decir la localización aproximada. Recuerda poner atención en la pronunciación de la ' $b$ ' y de la ' $v$ '. 
Tópico: Los sonidos de $<$ ti $>,<$ te $>,<$ di $>$ y $<$ de $>$

Objetivo(s): Promover una charla sobre las características de los hombres. Adquirir vocabulario. Percibir la distinción en la pronunciación de /t/y/d/ en portugués y en español. Desarrollar la práctica comunicativa a través de la temática 'gustos y personalidades'.

Actividad 1: Lee el cómic presentado a continuación:

Figura 1
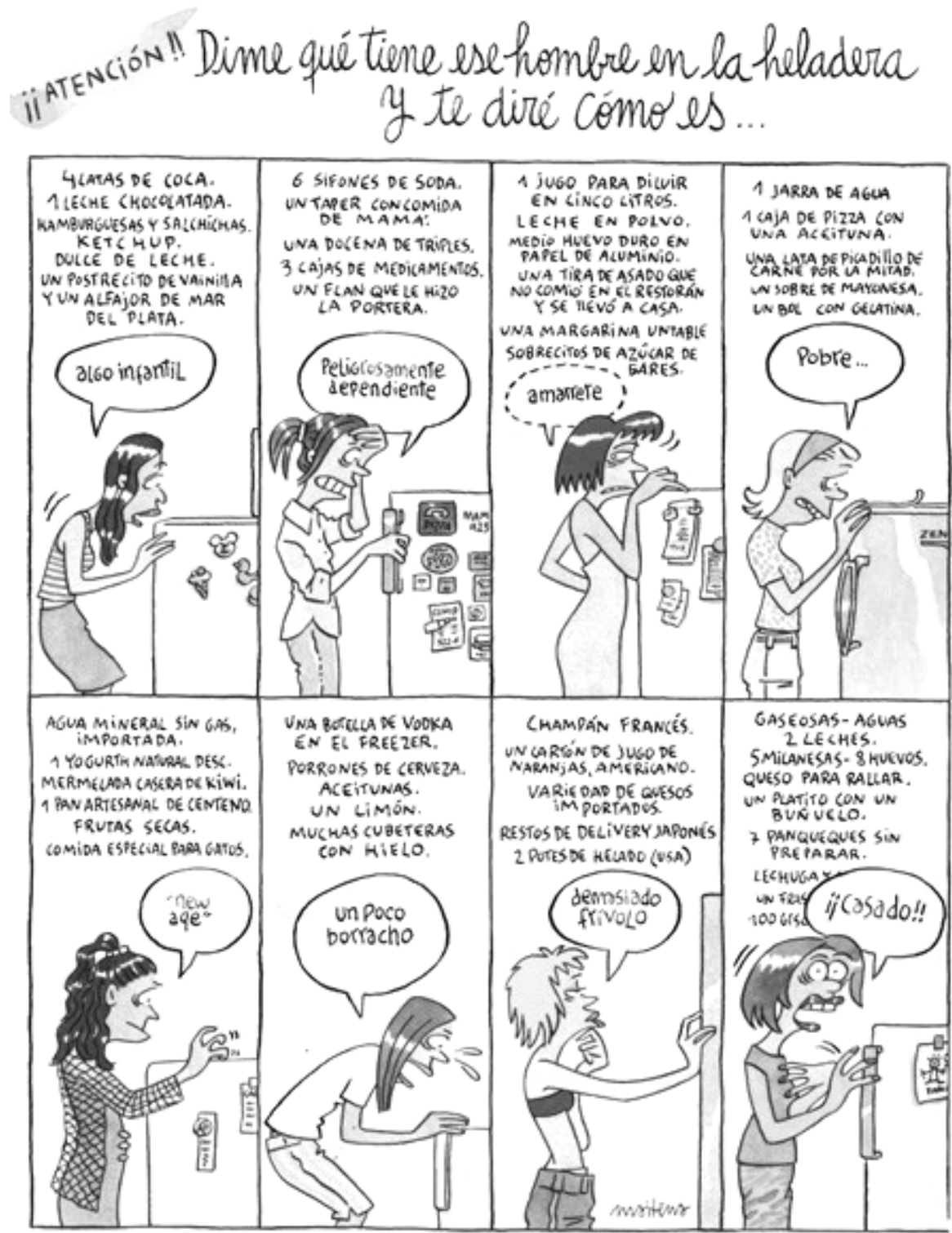

Maitena, Mujeres alteradas 5, Buenas Aires, Sudamericana Lumen, 2001.

Fuente: MARTIN, 2012a, p. 99. 
Actividad 2: En círculo, hablen sobre los alimentos que hay en la heladera de cada hombre y por cuál motivo las mujeres caracterizaron adjetivamente a ellos, piensen cuáles otras características podrían tener y discutan si esto no es una forma de prejuicio.

Actividad 3: Observa las características en el cuadro presentado a continuación, elige un pariente tuyo y describe a tus compañeros(as) su personalidad. Para contextualizar, descríbelo a partir de una situación ocurrida en una reunión familiar.

\section{TÍMIDO (A) - TIERNO (A) - TIRANO (A) - TENSO (A) - DIVERTIDO (A)}

DIVINO (A) - DENGOSO (A) - DEFENSOR (A)

Actividad 4: Observa las palabras: 'tímido, tenso, divino y divertido'. Nota que no hay diferencia en el significado al comparar con el portugués. Pero, ¿y la pronunciación? Pronuncia las palabras en portugués y en español, y comenta tu percepción sobre las distinciones observadas en la producción de las palabras.

\section{Tópicos: $\mathbf{L a}<\mathrm{Z}>$ y la $<$ s $>$}

Objetivo(s): Aprender palabras relativas al campo semántico de los alimentos. Entrenar la pronunciación a partir de la lectura oral de una receta de culinaria. Identificar la producción del fonema $/ \mathrm{s} /{ }^{10}$. Desarrollar la práctica comunicativa a través de la temática 'recetas'.

Actividad 1: Oye el dictado y escribe los nombres de alimentos que aparecen en la grabación:

Dictado: cereza - chorizo - manzana - zanahoria - zapallo - azúcar - fresa - queso pescado - sardina - sopa - ensalada

a) ¿Has encontrado alguna dificultad en la escritura de las palabras? ¿Cuál(es)?

b) ¿Se pronuncian igual los grafemas $<\mathrm{s}>\mathrm{y}<\mathrm{z}>$ en español? Justifica tu respuesta.

c) ¿En todas las variedades del español se pronuncia el grafema $<\mathrm{Z}>$, de 'manzana' y 'cereza', de la misma manera? Justifica tu respuesta. Actividad 2: Ahora, en parejas, deben elegir un alimento y crear una receta dulce o salada para presentar a sus compañeros de clase. En la presentación, recuerden poner atención en la pronunciación de los grafemas $<\mathrm{s}>,<\mathrm{ce}>,<\mathrm{ci}>\mathrm{y}<\mathrm{z}>$.

\footnotetext{
${ }^{10}$ Hay que aclarar que, a depender de la variedad de español que enseñe el profesor, la actividad se adaptará, con el fin de incluir el fonema $/ \theta /$ para las palabras cuyos grafemas son $<\mathrm{z}>\mathrm{o}<\mathrm{ce}>$ $\mathrm{y}<\mathrm{ci}>$. 


\section{Tópico: La $<$ ll $>$}

Objetivo(s): Promover una reflexión sobre las calles en que vivimos. Observar la pronunciación de la $<11>$ en español. Desarrollar la práctica comunicativa a través de la temática 'calles'.

Actividad 1: Lee el poema" "La calle Pandrossou", de Jaime Gil de Biedma y escúchalo recitado por Laura González en YouTube ${ }^{12}$ :

\section{La calle Pandrossou}

Bienamadas imágenes de Atenas.

En el barrio de Plaka,

junto a Monastiraki,

una calle vulgar con muchas tiendas.

$\mathrm{Si}$ alguno que me quiere

alguna vez va a Grecia

y pasa por allí, sobre todo en verano,

que me encomiende a ella.

Era un lunes de agosto

después de un año atroz, recién llegado.

Me acuerdo de que de pronto amé la vida,

porque la calle olía

a cocina y a cuero de zapatos.

a) ¿Te gustó el poema? Justifica tu respuesta.

b) ¿Cómo imaginas que sea la calle Pandrossou?

c) ¿Te gustaría vivir en una calle como esa? Justifica tu respuesta.

d) Con relación a las palabras "calle”, "allí”, "ellas” y "llegado”, ¿cómo se pronuncia el grafema $<11>$ ? ¿Has tenido alguna dificultad en la pronunciación? Cuál(es)?

e) ¿Pronuncias la $<11>$ de manera semejante a la recitada en el video? En caso negativo, ¿cómo pronuncias el grafema $<11>$ en español?

Actividad 2: Ahora, cuenta a tus compañeros de clase cómo es la calle donde vives, lo que hay en ella y si te gusta vivir allá. No te olvides de poner atención en la pronunciación de la "ll".

11 Retirado de: <https://www.poemas-del-alma.com/jaime-gil-de-biedma-la-calle-pandrossou. htm>. Acceso el 08 mar. 2021.

${ }^{12}$ Disponible en: $<$ https://www.youtube.com/watch? $=$ =nDCOQGFmT38 $>$. Acceso el 24 jun. 2021. Revista X, v. 16, n. 5, p. 1324-1354, 2021. 


\section{Tópico: Los sonidos de $<\mathbf{j e}>,<\mathbf{j o}>,<\mathbf{j a}>,<$ ge $>$ y $<$ gi $>$}

Objetivo(s): Adquirir vocabulario que remite al campo semántico personal y descriptivo; identificar la pronunciación de los grafemas $<\mathrm{je}>,\langle\mathrm{jo}\rangle,\langle\mathrm{ja}\rangle,\langle\mathrm{ge}\rangle \mathrm{y}<\mathrm{gi}\rangle$ a partir de la lectura y audición de un texto. Desarrollar la práctica comunicativa a través de la temática 'presentaciones y características'.

Actividad 1: En parejas, lean el siguiente texto ${ }^{13}$, del escritor uruguayo Eduardo Galeano, y escúchenlo recitado por el autor en el YouTube ${ }^{14}$. Pongan atención en la pronunciación de los sonidos de los grafemas $\langle\mathrm{je}>,\langle\mathrm{jo}>,<\mathrm{ja}>,\langle\mathrm{ge}>, \mathrm{y}\langle\mathrm{gi}>$. (Recuerden que estas consonantes se pronuncian de manera parecida con la pronunciación del dígrafo $<\mathrm{RR}>$ del portugués):

\section{La abuela}

La abuela de Bertha Jensen ${ }^{15}$ murió maldiciendo.

Ella había vivido toda su vida en puntas de pie, como pidiendo perdón por molestar, consagrada al servicio de su marido y de su prole de cinco hijos, esposa ejemplar, madre abnegada, silencioso ejemplo de virtud: jamás una queja había salido de sus labios, ni mucho menos una palabrota.

Cuando la enfermedad la derribó, llamó al marido, lo sentó ante la cama y empezó. Nadie sospechaba que ella conocía aquel vocabulario de marinero borracho. La agonía fue larga. Durante más de un mes, la abuela vomitó desde la cama un incesante chorro de insultos y blasfemias de los bajos fondos. Hasta la voz le había cambiado. Ella, que nunca había fumado ni bebido nada que no fuera agua o leche, puteaba con voz ronquita. Y así, puteando, murió; y hubo un alivio general en la familia y en el vecindario.

Murió donde había nacido, en el pueblo de Dragor, frente a la mar, en Dinamarca. Se llamaba Inge. Tenía una linda cara de gitana. Le gustaba vestir de rojo y navegar al sol.

a) ¿Cómo crees que se pronuncian los grafemas $<\mathrm{je}>,<\mathrm{jo}>,<\mathrm{ja}\rangle,<\mathrm{ge}>$ y $<$ gi $>$ ? ¿Encontraste alguna dificultad? ¿Cuál(es)?

Actividad 2: Tomando como base la temática del texto "La abuela", piensa y describe una persona real o ficticia, presentando sus características. Puedes imaginar una persona mal humorada o muy alegre, por ejemplo. Después, presenta la descripción de la persona

\footnotetext{
${ }^{13}$ GALEANO, Eduardo. Mujeres. 1. ed. Buenos Aires: Siglo Veintiuno Editores, 2015. p. 40.

${ }^{14}$ Disponible en: <https://www.youtube.com/watch?v=uTYjzZ5EUVE $>$. Acceso el 05 jul. 2021.

15 'Jensen' e 'Inge', presentados en el texto 'La abuela', se pronuncian ['dzensen] e ['inge] por ser nombres extranjeros.
} 
a tus compañeros e intenten adivinar si la persona descrita es real o no. Recuerda poner atención en la pronunciación de los grafemas $<$ je $>,<$ jo $>,<j a>,<$ ge $>$ y $<$ gi $>$.

\section{Tópico: La $<\mathbf{r}>$}

Objetivo(s): Percibir la diferencia entre los sonidos vibrantes [r] y [r]. Desarrollar la consciencia fonológica con trabalenguas. Desarrollar la práctica comunicativa a través de la temática 'rutina y horas'.

Actividad 1: De forma individual o en parejas, elige una de las tarjetas para jugar el bingo. Marca las palabras sorteadas y grita ‘ ¡bingo!' así que hayas completado la tarjeta. Palabras para el sorteo: guerra, guitarra, guerrera, churros, perro, corral, carreta, ahorra, radio, roca, ron, arrogante, reloj, reto, germen, cantar, naranja, garaje, careta, ahora, arena, mira, pera, farola, caro, aroma, hora, muro, aro, pájaro, gris, grande.

Tabla 1: Tarjetas para la actividad 1 del tópico "la $<\mathrm{r}>$ ".

\begin{tabular}{|c|c|c|c|}
\hline guerra & germen & guerra & perro \\
\hline cantar & guitarra & careta & guitarra \\
\hline naranja & guerrera & germen & cantar \\
\hline churros & garaje & corral & ahora \\
\hline carreta & naranja & churros & radio \\
\hline cantar & guitarra & pera & garaje \\
\hline arena & ahorra & naranja & guerrera \\
\hline guerrera & mira & farola & roca \\
\hline perro & ahora & perro & caro \\
\hline carreta & corral & aroma & corral \\
\hline arena & churros & ahorra & carreta \\
\hline farola & mira & ahora & hora \\
\hline aroma & corral & arrogante & reloj \\
\hline carreta & muro & hora & churros \\
\hline ron & arena & reto & arena \\
\hline churros & caro & farola & mira \\
\hline reloj & aro & pájaro & reto \\
\hline pájaro & arrogante & guitarra & grande \\
\hline roca & gris & arrogante & aro \\
\hline reto & cantar & garaje & reloj \\
\hline
\end{tabular}


Actividad 2: En grupos de 3 o 4 estudiantes, lean los trabalenguas $^{16}$ de las tarjetas presentadas a continuación

Tabla 2: Tarjetas para la actividad 2 del tópico "la $<\mathrm{r}>$ ".

\begin{tabular}{|c|c|}
\hline $\begin{array}{l}\text { Ferrocarril } \\
\text { Erre con erre, guitarra; } \\
\text { erre con erre, carril: } \\
\text { rápido ruedan los carros, } \\
\text { rápido el ferrocarril. }\end{array}$ & $\begin{array}{l}\text { El burrito barrigón } \\
\text { El burrito barrigón } \\
\text { ayer se dio un resbalón. } \\
\text { Por andar detrás de un carro, } \\
\text { se cayó dentro del barro. } \\
\text { ¡Qué burrito picarón, } \\
\text { el burrito barrigón! }\end{array}$ \\
\hline $\begin{array}{l}\text { El burro y el perro } \\
\text { Un burro comía berros } \\
\text { y el perro se los robó, } \\
\text { el burro lanzó un rebuzno } \\
\text { y el perro al barro cayó. }\end{array}$ & $\begin{array}{c}\text { Curro } \\
\text { Estando Curro en un corro, } \\
\text { con el Guerra y con Chicorro, } \\
\text { dijo Curro: - Yo me escurro de este corro, } \\
\text { con el Guerra y con Chicorro, } \\
\text { en el carro de Socorro. }\end{array}$ \\
\hline $\begin{array}{l}\text { El ratón } \\
\text { Borracho un ratón robó } \\
\text { un ramo de rosas rojas. } \\
\text { El rabo se le enredó } \\
\text { y rodó de rosa en rosa. }\end{array}$ & $\begin{array}{c}\text { Trabalenguas de los perros } \\
\text { Había un perro } \\
\text { debajo de un carro, } \\
\text { vino otro perro } \\
\text { y le mordió el rabo. } \\
\text { Corre, corre por la calle arriba, } \\
\text { corre, corre por la calle abajo. }\end{array}$ \\
\hline
\end{tabular}

Después de la lectura de los trabalenguas, contesten a las siguientes preguntas: a) ¿La $<\mathrm{r}>$ es más difícil en algún contexto silábico? ¿Cuál(es)?

b) ¿Se pronuncia igual la $<\mathrm{r}>$ de las palabras 'hora' y 'grande' en español y en portugués? Justifica tu respuesta.

c) ¿Hay diferencias en la pronunciación del grafema $<\mathrm{r}>$ en 'guitarra' y 'naranja' en español? Justifica tu respuesta.

Actividad 3: En parejas, comenten sus rutinas, pensando en los días que tienen clases: ¿qué hacen antes de ir al colegio? ¿Qué hacen durante el día? ¿A qué hora vuelven de la escuela? ¿Qué les gusta hacer los fines de semana? Recuerden poner especial atención en las vibrantes del español.

\footnotetext{
${ }^{16}$ Retirado de: $<$ https://pt.slideshare.net/joserodolfochavez/trabalenguas-para-pronunciar-la-r $>$. Acceso el: 13 feb. 2021.
} 


\section{Tópico: La $<$ l $>$}

Objetivo(s): Promover una charla sobre un cómic y los significados que él puede presentar. Identificar la pronunciación del grafema $<1>$ en la lengua española. Desarrollar la práctica comunicativa a través de la temática 'opiniones'.

Actividad 1: Al contrario del portugués, en la lengua española el grafema $<\mathrm{l}>$ no se pronuncia como [u], sino como [1]. De esa manera, lee el cómic ${ }^{17}$ del historietista Quino en voz alta y pon atención en la pronunciación de las palabras con el grafema $<1>$.

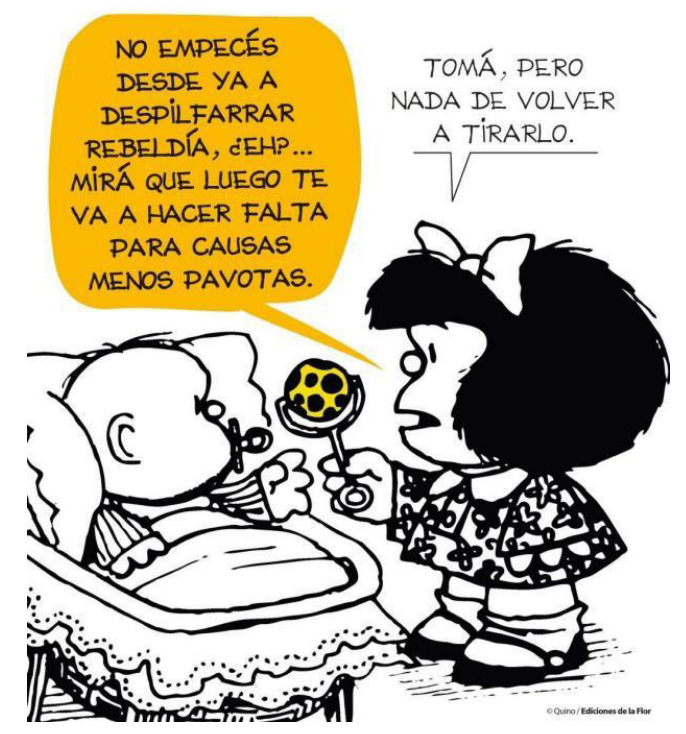

a) ¿Qué has entendido del cómic? ¿Qué crees que él pretende informar?

b) ¿Cómo has pronunciado el fonema /1/ en las palabras "despilfarrar", "rebeldía" y "falta"?

c) Si fuera en portugués, ¿se pronunciaría igual que en español la $<1>$, en palabras como 'falta' y 'rebeldia', por ejemplo? Justifica tu respuesta.

d) Ahora el profesor lee en voz alta el cómic, con el fin de que los alumnos comprueben si su pronunciación está adecuada.

Actividad 2: Comparte con tus compañeros de clase tu interpretación sobre el cómic, lo qué entendiste de la historia y lo qué te hizo pensar y compara tu respuesta con las de tus compañeros, con el fin de ver si están de acuerdo o no. Recuerda poner atención en la pronunciación de la ' 1 '.

17 Retirado de: <https://i.pinimg.com/originals/f8/d5/20/f8d520193a5f3be987cee9ce424e4c62.jpg> Acceso el: 08 mar. 2021.

Revista X, v. 16, n. 5, p. 1324-1354, 2021. 


\section{CONCLUSIÓN}

En esta investigación, analizamos la colección 'Síntesis - curso de lengua española', de Ivan Martin, con el fin de verificar si el material contempla la enseñanza de la pronunciación; en caso positivo, queríamos identificar los sonidos abordados en la colección y también verificar si se contemplaba la variación fónica en las actividades. El análisis demostró que hay poco espacio para tratar de la pronunciación en los manuales y que tan solo había tópicos resumidos sobre pronunciación. Discutimos los trece tópicos puestos en el primer libro como 'Pronunciación' a partir de autores e investigadores del campo de la fonética y fonología del portugués y español; además, comentamos algunas actividades dedicadas a la competencia oral que se tomaron de los tres ejemplares de la colección, con el fin de ver si trataban del desarrollo de la pronunciación.

Concluimos que, aunque la colección señale algunos tópicos sobre pronunciación de vocales y consonantes en las 'reglas generales' y en el poema 'La luna', el abordaje no es suficiente para que los aprendices de la enseñanza secundaria perciban y se apropien de los fenómenos presentados. Hay, en el CD, la grabación de 'La luna' en distintos acentos, o sea, en este momento, el autor demuestra que existen distintas variedades del español, pero no localiza de dónde son estos hablantes, dejando lagunas en la información y en el aprendizaje.

Otro punto que analizamos es que no hay actividades que tratan específicamente de la producción de sonidos, por lo tanto, no se puede desarrollarlas. Las actividades de oralidad, en general, no se fijan en una propuesta comunicativa similar al habla real, sino en el ejercicio de los contenidos de cada capítulo - principalmente los gramaticales.

Con el fin de presentar un aporte al docente y al estudiante, propusimos actividades en las que se tratasen algunos tópicos de pronunciación descritos en los libros, poniendo énfasis no solo en la pronunciación, sino también en el desarrollo de la conversación. Por lo tanto, en cada tópico, buscamos tratar un asunto comunicativo. Cabe señalar que estas son tan solo sugerencias considerando los puntos que pueden ser más difíciles a los aprendices brasileños de la secundaria y que las mismas actividades se pueden adaptar para otros públicos-meta.

Entre las posibilidades futuras de investigación, es posible analizar los audios utilizados para la comprensión auditiva, observando, por ejemplo, las variedades presentadas. Así como se puede discutir cada una de las actividades propuestas para la oralidad, también sería fundamental dar continuidad al estudio, enfocando en la relevancia 
de la comprensión auditiva para el desarrollo del componente oral en la adquisición del español por brasileños.

\section{AGRADECIMIENTOS}

Agradecemos la posibilidad de desarrollar este trabajo con la financiación de becas de Iniciación Científica por PIBIC/CNPq y por Fapergs y de beca de Posgrado por CAPES/CNPq.

\section{REFERENCIAS}

ALVES, J. B. Ensino de pronúncia do espanhol como língua estrangeira: reflexões e propostas didáticas. 2019. 240 f. Tese (Doutorado em Linguística e Língua Portuguesa) - Universidade Estadual Paulista "Júlio de Mesquita Filho", Araraquara/SP, 2019. Disponible en: https://repositorio.unesp.br/handle/11449/183144. Acceso el: 06 jul. 2021.

ALVES, U. K. A explicitação dos aspectos fonético-fonológicos da L2: teoria e pesquisa na sala de aula. In: LAMPRECHT, R. R.; BLANCO-DUTRA, A. P.; SCHERER, A. P. R.; BARRETO, F. M.; BRISOLARA, L. B.; SANTOS, R. M.; ALVES, U. K. Consciência dos sons da língua: subsídios teóricos para alfabetizadores, fonoaudiólogos e professores de língua inglesa. Porto Alegre: EDIPUCRS, 2012. p. 211-230.

ALVES, U. K. Ensino de pronúncia na sala de aula de língua estrangeira: questões de discussão a partir de uma concepção de língua como sistema adaptativo complexo. Revista Versalete, Curitiba, v. 3, n. 5, jul. - dez., p. 392-413, 2015. Disponible en: http:// www.revistaversalete.ufpr.br/edicoes/vol3-05/392UbirataAlvesPRONTO.pdf. Acceso el: 22 abr. 2020.

BRASIL. Secretaria de Educação Básica. Ministério da Educação. Orientações Curriculares para o Ensino Médio: Linguagens, códigos e suas tecnologias. Brasília, 2006. Disponible en: http://portal.mec.gov.br/seb/arquivos/pdf/book_volume_01_ internet.pdf. Acceso el: 22 de abril de 2020.

BRISOLARA, L. B. Fonemas, sonidos y letras. In: BRISOLARA, L. B.; SEMINO, M. J. I. ¿Cómo pronunciar el español? La enseñanza de la fonética y la fonología para brasileños: ejercicios prácticos. Campinas, SP: Pontes Editores, 2016a. p. 15-39.

BRISOLARA, L. B. El sistema vocálico del español y del portugués. In: BRISOLARA, L. B.; SEMINO, M. J. I. ¿Cómo pronunciar el español? La enseñanza de la fonética y la fonología para brasileños: ejercicios prácticos. Campinas, SP: Pontes Editores, 2016b. p. 41-54. 
BRISOLARA, L. B. El sistema consonántico del español y del portugués. In: BRISOLARA, L. B.; SEMINO, M. J. I. ¿Cómo pronunciar el español? La enseñanza de la fonética y la fonología para brasileños: ejercicios prácticos. Campinas, SP: Pontes Editores, 2016c. p. 55-74.

BRISOLARA, L. B.; MACHRY DA SILVA, S. O sistema consonantal do espanhol. In: ALVES, U. K; MACHRY DA SILVA, S; BRISOLARA, L. B.; ENGELBERT, A. P. P. F. Fonética e fonologia de línguas estrangeiras: subsídios para o ensino. Campinas, SP: Pontes Editores, 2020. p. 159-188.

BUCHENER, L. K.; COSTA, L. T. Análise de atividades acerca do ensino da pronúncia em livros didáticos. Interfaces, Paraná, v. 10, n. 1. p. 162-177, 2019. Disponible en: https://revistas.unicentro.br/index.php/revista_interfaces/article/view/5839. Acceso el: 22 abr. 2020.

CONSEJO DE EUROPA. Marco común europeo de referencia para las lenguas: aprendizaje, enseñanza, evaluación. [recurso electrónico] Madrid: Instituto Cervantes, 2002. Disponible en: https://cvc.cervantes.es/ensenanza/biblioteca_ele/marco/cvc_mer. pdf. Acceso el: 06 jul. 2021.

FRANCIS, M.; PONTES, V. O. As variedades linguísticas nas atividades de tradução em livros didáticos de espanhol do PNLD - 2011. Mutatis Mutandis: Revista Latinoamericana de Traducción. v. 7, n. 1, p. 83-99, 2014. Disponible en: https:// dialnet.unirioja.es/servlet/articulo?codigo=5012715. Acceso el: 22 abr. 2020.

HONORATO, S. E. O desenvolvimento da oralidade nos diálogos em livros didáticos de língua espanhola para o ensino médio. Monografia (Especialização em Língua e Literatura com ênfase nos Gêneros do Discurso) - Universidade do Extremo Sul Catarinense, Criciúma, 2010. Disponible en: http://repositorio.unesc.net/handle/1/908. Acceso el: 22 abr. 2020.

HUALDE, J. I.; OLARREA, A.; ESCOBAR, A. M.; TRAVIS, C. A. Introducción a la lingüística hispánica. $2^{\mathrm{a}}$ ed. Cambridge: Cambridge University Press, 2010.

GIL FERNÁNDEZ, Juana. Fonética para profesores de español: de la teoría a la práctica. Madrid: Arco/Libros, 2007.

KAUARK, F. S.; OLIVEIRA, M. N. Fonética e fonologia: aulas de pronúncia de E/LE no Brasil. Práxis Educacional, Vitória da Conquista, v. 7, n. 11. jul./dez., p. 191-204, 2011. Disponible en: https://periodicos2.uesb.br/index.php/praxis/article/view/672. Acceso el: 22 abr. 2020. 
MARTIN, I. Síntesis: curso de lengua española. v. 1. São Paulo: Ática, 2012a.

MARTIN, I. Síntesis: curso de lengua española. v. 2. São Paulo: Ática, 2012b.

MARTIN, I. Síntesis: curso de lengua española. v. 3. São Paulo: Ática, 2012c.

QUILIS, A. Tratado de fonología y fonética españolas. $6^{\text {a }}$ ed. Madrid: Editorial Gredos, 1999.

QUILIS, A. Principios de fonología y fonética españolas. 6a ed. Madrid: Arco/Libros, 2005 .

REAL ACADEMIA ESPAÑOLA; ACADEMIA AMERICANA DE LA LENGUA ESPAÑOLA. Nueva gramática de la lengua española: fonética y fonología. Barcelona: Espasa, 2011.

SANDES, E. I. de A. Análise das dificuldades dos estudantes brasileiros de E/LE na percepção e na produção dos sons aproximantes e nasais em língua espanhola. 2010. 269 f. Tese (Doutorado em Letras) - Universidade de São Paulo, São Paulo, 2010. Disponible en: https://www.teses.usp.br/teses/disponiveis/8/8145/tde-14102010-091300/en.php. Acceso el: 26 jul. 2020.

SILVA, K. C. D. da. Ensino-aprendizagem do espanhol: o uso interlinguístico das vibrantes. 2007. Dissertação (Mestrado em Linguística) - Universidade Federal do Ceará, Fortaleza, 2007. Disponible en: http://www.repositorio.ufc.br/bitstream/ riufc/8769/1/2007_dis_kcdsilva.pdf. Acceso el: 24 jul. 2020.

SOARES, F. P. M.; MERCEDES, C. C. Lengua, sociedad e interculturalidad en la enseñanza/aprendizaje de portugués y español. Foz do Iguaçu, PR: EDUNILA, 2019. E-book. Disponible en: https://portal.unila.edu.br/editora/livros/e-books/lengua sociedad_interculturalidad.pdf. Acceso el: 05 mar. 2021.

Recebido em: 21 de mai. 2021. Aceito em: 07 jul. 2021. 